\title{
Modeling Road Surface Temperature from Air Temperature and Geographical Parameters-Implication for the Application of Floating Car Data in a Road Weather Forecast Model
}

\author{
Yumei Hu, Esben Almkvist, TORBJÖRn Gustavsson, AND JÖRGEN BOGREN \\ Department of Earth Sciences, University of Gothenburg, Gothenburg, Sweden
}

(Manuscript received 26 May 2018, in final form 12 February 2019)

\begin{abstract}
Precise forecasts of road surface temperature (RST) and road conditions allow winter roads to be maintained efficiently. The upcoming "big data" application known as "floating car data" (FCD) provides the opportunity to improve road weather forecasts with measurements of air temperature $T_{a}$ from in-car sensors. The research thus far with regard to thermal mapping has mainly focused on clear and calm nights, which occur rarely and during low traffic intensity. It is expected that more than $99 \%$ of the FCD will be collected during conditions other than clear and calm nights. Utilizing 32 runs of thermal mapping and controlled $T_{a}$ surveys carried out on mostly busy roads over one winter season, it was possible to simulate the use of $T_{a}$ and geographical parameters to reflect the variation of RST. The results show that the examined route had several repeatable thermal fingerprints during times of relatively high traffic intensity and with different weather patterns. The measurement time, real-time weather pattern, and previous weather patterns influenced the spatial pattern of thermal fingerprints. The influence of urban density and altitude on RST can be partly seen in their relationship with $T_{a}$, whereas the influence of shading and sky-view factor was only seen for RST. The regression models with $T_{a}$ included explained up to $82 \%$ of the RST distribution and outperformed models that are based only on the geographical parameters by as much as $30 \%$. The performance of the models denotes the possible utility of $T_{a}$ from FCD, but further investigation is needed before moving from controlled $T_{a}$ measurements to $T_{a}$ from FCD.
\end{abstract}

\section{Introduction}

In high-latitude countries, such as Sweden, slippery road conditions are often seen in wintertime. To keep roads safe and open over winter, it is important for the winter road maintenance engineers to have precise road weather forecasts. By 2020, about one in five cars on the road will be connected to the Internet and its storage (hereinafter the "cloud"), which amounts to approximately one-quarter of a billion vehicles (Morris et al. 2018). With such a large number of cars connected to the cloud, many of the in-car sensors can, if handled properly, be incorporated into a weather forecast model. Weather-related "floating car data" (FCD) are likely to be an important "big data" application in the near future. For example, currently (March 2018) more than 200 cars in the Gothenburg region deliver data to the cloud and aid winter road maintenance operations

Corresponding author: Esben Almkvist, esben.almkvist@ klimator.se personnel in their decisions. The number of observations from such vehicles is already enormous relative to the number from the fixed weather stations. The vehicles cover an area and have a spatial resolution both of which are simply unrealistic to achieve with fixed stations. If every car in the region were connected to the cloud, the volume of data would increase 100-fold-a true big-data application - and instigate a new paradigm in road weather and probably most weather models.

Of all the in-car sensors, the air temperature $T_{a}$ sensor is probably the easiest to include in weather-related applications. The $T_{a}$ sensor is often installed inside one of the side mirror housings, inside the fenders or ahead of the vehicle's radiator. The height of $T_{a}$ sensor depends on its location and the type of car, but it is normally located at a level below $2 \mathrm{~m}$. The output of the $T_{a}$ sensor, which is available from the connected cars, is considered as a parameter for estimating the road surface temperature (RST), which is crucial for the determination of slippery conditions. In this study, thermalmapping measurements, that is, RST and $T_{a}$ measurements, were used to study the usability of FCD. The $T_{a}$ recorded 
during the course of thermal mapping is regarded as though they are from connected cars.

RST can vary quite a bit across the road network because of the influence of different geographical parameters, such as altitude, land use, shading $S_{r}$, sky-view factor $\psi_{s}$, topography and so on. To quantify the influence across the road network, it is necessary to have route-based RST observations. With an infrared instrument, thermal mapping is often used to measure and indicate the spatial variation of RST (Thornes 1991) along the road network between the road weather stations. In this study, the spatial variation of RST plotted against distance for a particular route is referred to as a thermal fingerprint, after Thornes (1991). To capture the minimum RST and compare RST between different road sections, it is suggested that thermal mapping should be carried out during the latter part of the night (Thornes 1991). This has also been shown in previous studies (Table 1), with thermal mapping mostly carried out overnight, especially during extreme conditions, for example, clear calm nights. In particular, most of the research (Table 1), which has been focused on the influence of geographical parameters on route-based RST, used thermal-mapping data collected overnight as well. Of those studies, only Chapman et al. (2001) comprehensively studied the influence of many different geographical parameters (altitude, topography, $\psi_{s}$, urbanicity, and roadbed materials) on RST. In the study, measurements carried out late at night between 0100 and 0500 (local time) under different weather patterns were used; other studies either focused on one certain parameter or only clear, calm conditions. Several studies also used daytime thermal-mapping data for the same aim (Table 1); however, only certain parameters were included, for instance, $S_{r}, \psi_{s}$, or roadbed material. A key question is whether the relationship between temperature and geographical parameters is repeatable across several measurements.

For the most comprehensively studied period, 01000500 (local time), the traffic intensity is often very low. For instance, based on the hourly traffic-volume data (ÅDT) provided by the Swedish Transport Administration (STA), it was found that, in the Borås region, only $3 \%$ of the daily traffic between October 2011 and March 2012 occurred over the most studied time (0100-0500) (Table 2). In addition, clear, calm weather conditions are not very common in the region. Based on the hourly surface sky-cover data from the National Centers for Environmental Information (NCEI, formerly the National Climatic Data Center; see sections $2 \mathrm{~b}$ and $2 \mathrm{c}$ ), only $9.9 \%$ of the time between November 2011 and March 2012 in the Borås region had clear weather conditions (Table 3). Since the weather data were taken from two airport sites, it is possible that the local wind speed along the roads in the region was lower, so all wind speeds were taken into account in the following text. If a limit of $2 \mathrm{~m} \mathrm{~s}^{-1}$ were set as a criterion for calm weather, a limit found from Pasquill and Smith (1983), Karlsson (2000), and Mahrt (2011), clear and calm situations would only amount to $2 \%$ in the region. Combining the above two aspects (clear: $9.9 \%$ and traffic: $3 \%$ ), most of the literature thus far has focused on $0.3 \%$, or less than $1 \%$ of what people on the road will actually encounter when driving; in other words, more research is needed to properly handle more than $99 \%$ of the FCD that will be collected. For most of the time in a day, detailed measurements of RST across the road network are often missing when utilizing the commonly used thermalmapping method. To improve road weather forecasts for periods with more road users under different weather patterns, measurements of RST variation across the road network during the corresponding period and weather are needed. In particular, using the measurements in this study, not only the influence of different geographical parameters on RST can be quantified and used for road weather forecasts, but also the method of how to make use of FCD in RST forecasts can be investigated. Most modern cars are equipped with several sensors and devices that are relevant for investigating the road weather. Here, the focus will be exclusively on how to use the $T_{a}$ sensor, but many other relevant data sources exist, for example, windscreen wipers (precipitation), antilock braking systems (friction estimation), and traction control (friction estimation) (Petty and Mahoney 2007; Mahoney and O'Sullivan 2013). In recent years, cars have been able to communicate their data to the cloud in real time, which means that this type of data can be utilized in a road weather forecast model. $T_{a}$, which is closely related to RST (Gustavsson 1990; Bogren and Gustavsson 1991; Lindqvist 1992), is assumed to reflect the spatial variation of RST under different weather patterns to a certain extent. It is interesting to see if the variation in RST across the regional road network as a consequence of the interaction of geographical parameters will also be evident in the variation of $T_{a}$. If controlled $T_{a}$ measurements can be successfully used in modeling RST, this may have some implications for application of $T_{a}$ from the real FCD. The FCD will be recorded during different weather patterns and mostly during times of relatively high traffic flow. Road users will benefit if the FCD can be used to improve road weather forecasts, thereby enhancing drivers' safety.

Therefore, the aims of this study are 1) to examine whether thermal fingerprints are related to a given weather pattern with relatively high traffic intensity and characterize the corresponding spatial variation of RST and $\left.T_{a}, 2\right)$ to examine and compare the influence of 


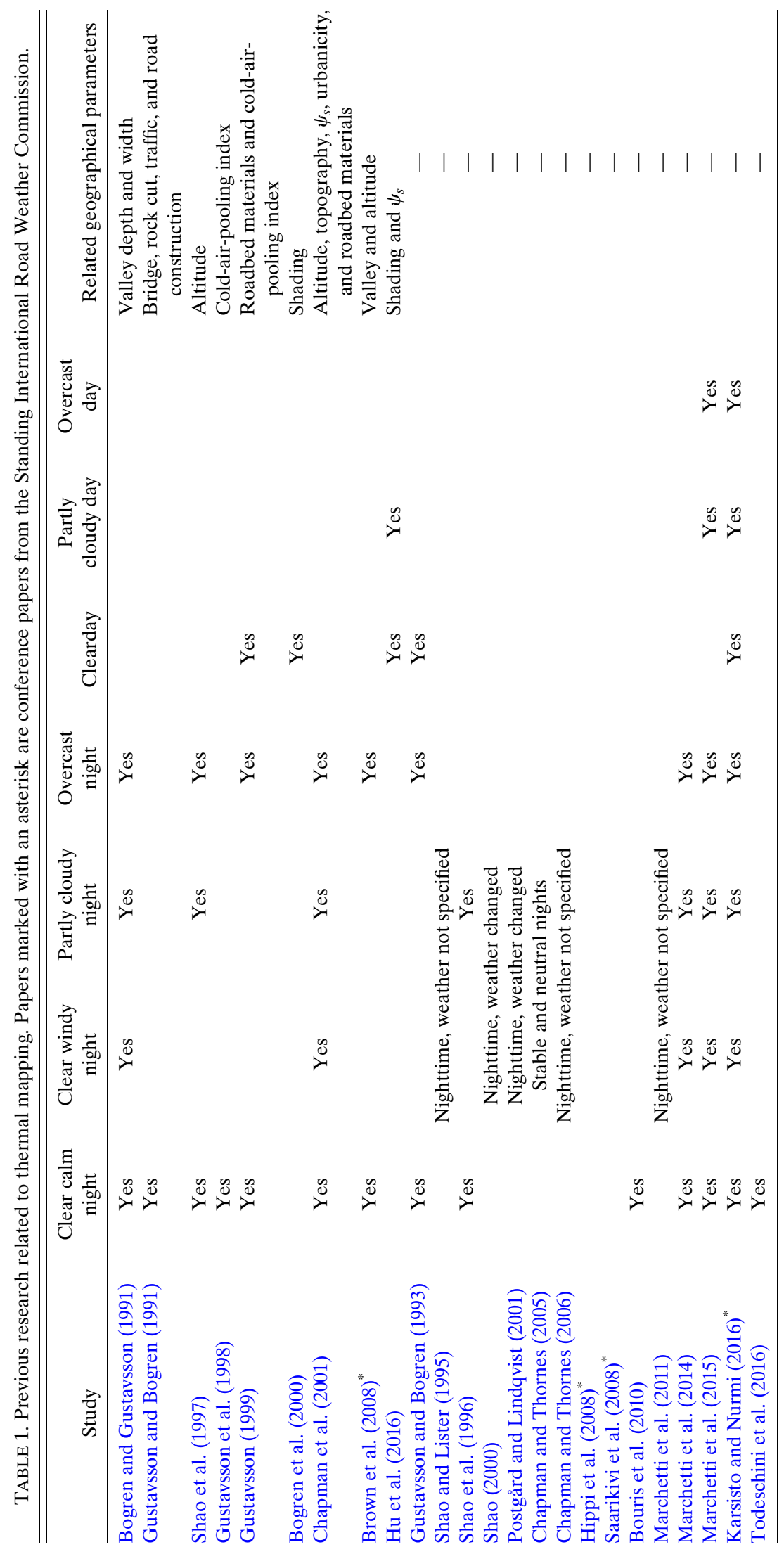


TABLE 2. Traffic-volume information in the Borås region.

\begin{tabular}{lcc}
\hline \hline Station & Latter part of night (0100-0500) & Other time \\
\hline S9544 & $3.5 \%$ & $96.5 \%$ \\
S9561 & $2.6 \%$ & $97.4 \%$ \\
S9776 & $3.9 \%$ & $96.1 \%$ \\
S9777 & $2.6 \%$ & $97.4 \%$ \\
\hline
\end{tabular}

geographical parameters on RST and $T_{a}$ under these conditions, and 3) to learn how to use the controlled $T_{a}$ and geographical parameters to build a model for RST forecasting between stations and examine the implications for the application of $T_{a}$ from FCD.

\section{Method}

\section{a. Study area}

This study was carried out in Borås, in southwestern Sweden (Fig. 1). The area is about $30 \mathrm{~km}$ from north to south and $15 \mathrm{k} \mathrm{m}$ from west to east. Roads 42,182 , and 183 were chosen since they encompass different land uses and have a relatively large variation in geographical parameters whose influence is expected to be significant. The altitude in the area ranges from around 100 to $300 \mathrm{~m}$, with the survey routes running mainly parallel to the direction of the valleys.

\section{b. Traffic data}

ÅDT from four stations (Fig. 1), provided by the STA, were used to calculate the traffic volumes at different times of the day, as shown in Table 2. Data from these stations were acquired over different periods. For stations 9561 and 9777 the data start from 1 October 2011, for station 9544 the data start from 1 November 2011, and for station 9776 the data start from 1 January 2012. For all the stations the data end on 31 March 2012.

\section{c. Surface sky-cover data and Mesan data}

The hourly surface sky-cover data from two site-based stations (Fig. 1) were accessed from the NCEI (https:// www.ncdc.noaa.gov/isd/data-access) and were used to calculate the weather pattern conditions in the study area, as shown in Table 3. The data from these two stations should represent the meteorological conditions in the study area since the thermal routes were situated between them. Note that the result is based on the valid data; on average, $25 \%$ of missing data were excluded from the analysis.

In addition, the hourly total cloud information from the meteorological mesoscale analysis model "Mesan" (Häggmark et al. 2000), provided by the Swedish Meteorological and Hydrological Institute (SMHI), was used to show the cloudiness distribution ahead of, and
TABLE 3. Percentages of specific weather patterns in the Västra Götland region, based on stations from NCEI.

\begin{tabular}{lrccc}
\hline \hline Station & Clear & Overcast & Partly cloudy & Obscured \\
\hline 25260 & $4.0 \%$ & $30.1 \%$ & $54.8 \%$ & $11.1 \%$ \\
25500 & $15.9 \%$ & $29.9 \%$ & $50.0 \%$ & $4.2 \%$ \\
\hline
\end{tabular}

during, each thermal mapping. The spatial resolution of the data is $11 \mathrm{~km}$.

\section{d. Thermal mapping and air temperature measurements}

From the end of January to the beginning of March in 2012, thermal-mapping surveys were carried out on the selected roads. At this latitude, the effect from the sun is quite limited and shading effects are not as pronounced in the last few days of January and at the beginning of February as later during the winter, that is, during the last few days of February and at the beginning of March. The clear-sky global radiation in the Borås area at noon is about $248 \mathrm{~W} \mathrm{~m}^{-2}$ on 1 February as compared with about $401 \mathrm{~W} \mathrm{~m}^{-2}$ on 1 March (Haurwitz 1945, 1946). Therefore, the earlier measurements are considered to be early winter whereas the later measurements are considered to be late winter. Measurements started from where roads 40 and 42 crossed in the Borås city center, along roads 42,182 , and 183 and ended on road 42 again (Fig. 1). The road network was about $72 \mathrm{~km}$ long, and each measurement took about $1 \mathrm{~h}$. The datalogger was set to record data every $30 \mathrm{~m}$.

During the experiment, a total of 32 thermal-mapping measurements were taken (Table 4), 14 during daytime and 18 after sunset. During the course of each survey, $T_{a}$ was also recorded by installing a sensor on the roof of the vehicle at 2-m level. The air temperature sensor was placed inside a radiation shield so that the influence of direct shortwave radiation was minimized. To cover different times of the day, different start times were chosen. For more details about the infrared thermometers used for thermal mapping, see Hu et al. (2016).

For each thermal-mapping run, observations of RST, air temperature at $2 \mathrm{~m} T_{\text {rwis }}$, and wind speed at $5 \mathrm{~m}$ from the six site-based road weather information system (RWIS) stations in the study area were provided by the STA (Fig. 1). Wind speed data were used to provide background meteorological information for each thermal-mapping run, and RST and $T_{\text {rwis }}$ were used to remove the temporal trend of thermalmapping data.

After detrending, all the thermal-mapping runs were classified into groups, where each member had a similar thermal fingerprint. The grouping used the hierarchical binary clustering method to examine whether the 


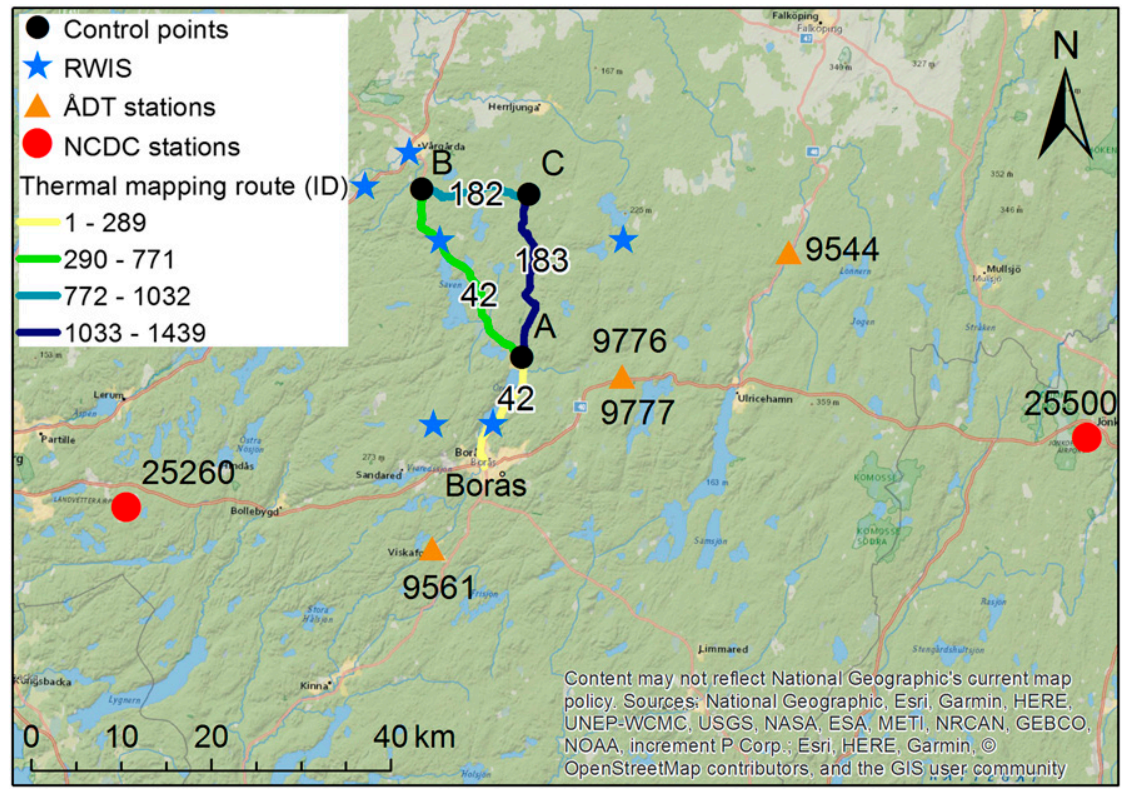

FIG. 1. Locations of the study area, NCEI stations, road weather information system stations, ÅDT stations, and the thermal-mapping route.

recorded thermal fingerprints were repeatable over different time periods. Hierarchical binary clustering method uses two strategies, agglomerative (bottom up) and divisive (top down) (Hastie et al. 2008). Agglomerative strategy, which starts at the bottom and at each level merges two measurements into one cluster, was used in this study. Hierarchical binary clustering method requires the user to specify a measure of dissimilarity between groups before clustering. The hierarchical binary clustering method outputs a dendrogram with detailed description of the hierarchical clustering in graphical format, which is easy to understand and therefore makes the clustering method to be widely used. For more information regarding the hierarchical binary clustering method, see Hastie et al. (2008).

In this study, for thermal fingerprints in a group to be considered repeatable, the group should include measurements from different dates. To group the thermal-mapping runs, the Pearson correlation coefficient $R$ between RST measurements from every two thermal-mapping runs was calculated, and $R$ was used in the clustering. The cutoff was set to 0.5 , which means thermal-mapping surveys with $R$ below 0.5 would not be classified into the same group. The choice of cutoff should not only ensure that the thermal mappings in the same group have similar thermal fingerprints, but also should produce as few groups as possible so that thermal mappings with similar thermal fingerprints are not grouped into different groups.
The sensitivity of using different cutoff values was tested, and 0.5 was chosen since the results fitted the requirements best. Figure 2 shows the dendrogram resulting from the hierarchical clustering. As shown, the thermal fingerprints were classified into 16 groups in total.

\section{e. Development of geographical parameters}

From the Swedish mapping, cadastral, and land registration authority (Lantmäteriet), road vector data, digital elevation model (DEM), land-use data, and a digital surface model (DSM), were all accessed and used to generate the geographical parameters used in this study. Most of the parameters were developed using the geographical information system (GIS) software ArcGIS desktop.

The road vector data were divided into $50-\mathrm{m} \mathrm{seg-}$ ments, and the thermal-mapping measurements and geographical parameters were spatially related to the segmented scaled road vertices. This segment-based approach facilitated quantitative analysis of the relationship between different geographical parameters and temperature. A segment length of $50 \mathrm{~m}$ was chosen to match the scale of the thermal mapping.

In total, five geographical parameters were investigated in this study. Altitude, extracted from the DEM with 2-m spatial resolution, was used to examine the influence of altitude on RST and $T_{a}$. Then, relative altitude, the difference between the altitude of each target segment and the average altitude of its surrounding area 
TABLE 4. Thermal-mapping measurements from 2012 used in this study. Repeatable groups are shown in boldface type. An asterisk indicates that the end time is on the following day. Here, ID indicates the measurement identifier.

\begin{tabular}{|c|c|c|c|c|c|c|}
\hline ID & Group & Date & Time & Weather pattern & Day/night & Wind speed $\left(\mathrm{m} \mathrm{s}^{-1}\right)$ \\
\hline M1 & 5 & 23 Jan 2012 & 1149-1300 & Partly cloudy & Daytime & 3.7 \\
\hline M2 & 15 & 23 Jan 2012 & $1419-1530$ & Partly cloudy & Daytime & 4.2 \\
\hline M3 & 4 & 27 Jan 2012 & $1011-1121$ & Overcast with precipitation & Daytime & 8.7 \\
\hline M4 & 14 & 27 Jan 2012 & $1358-1506$ & Overcast & Daytime & 7.6 \\
\hline M5 & 14 & 27 Jan 2012 & $1609-1720$ & Overcast & Nighttime & 7.4 \\
\hline M6 & 10 & 1 Feb 2012 & $1030-1140$ & Partly cloudy & Daytime & 2.8 \\
\hline M7 & 10 & 1 Feb 2012 & $1414-1529$ & Overcast with precipitation & Daytime & 3.4 \\
\hline M8 & 7 & 1 Feb 2012 & $1656-1816$ & Overcast with precipitation & Nighttime & 3.9 \\
\hline M9 & 7 & 2 Feb 2012 & $1821-1943$ & Partly cloudy & Nighttime & 4.0 \\
\hline M10 & 16 & 2 Feb 2012 & 2124-2239 & Partly cloudy & Nighttime & 3.0 \\
\hline M11 & 16 & 2 Feb 2012 & $2351-0104^{*}$ & Partly cloudy & Nighttime & 3.4 \\
\hline M12 & 16 & 6 Feb 2012 & 1803-1917 & Partly cloudy & Nighttime & 3.4 \\
\hline M13 & 13 & 6 Feb 2012 & 2057-2211 & Partly cloudy & Nighttime & 4.7 \\
\hline M14 & 13 & 6 Feb 2012 & $2345-0100^{*}$ & Partly cloudy & Nighttime & 4.8 \\
\hline M15 & 6 & 9 Feb 2012 & 1006-1118 & Partly cloudy & Daytime & 3.2 \\
\hline M16 & 12 & 9 Feb 2012 & $1400-1509$ & overcast & Daytime & 11.2 \\
\hline M17 & 12 & 9 Feb 2012 & $1659-1814$ & Partly cloudy & Nighttime & 12.7 \\
\hline M18 & 2 & 20 Feb 2012 & $1812-1931$ & Overcast with precipitation & Nighttime & 10.8 \\
\hline M19 & 3 & 20 Feb 2012 & $2106-2233$ & Overcast with precipitation & Nighttime & 10.0 \\
\hline M20 & 11 & 20 Feb 2012 & $2358-0128^{*}$ & Overcast with precipitation & Nighttime & 8.1 \\
\hline M21 & 9 & 29 Feb 2012 & 1801-1917 & Clear & Nighttime & 11.8 \\
\hline M22 & 9 & 29 Feb 2012 & 2104-2218 & Overcast & Nighttime & 5.3 \\
\hline M23 & 9 & 29 Feb 2012 & $2352-0105^{*}$ & Overcast & Nighttime & 6.0 \\
\hline M24 & 1 & 2 Mar 2012 & $1026-1137$ & Clear & Daytime & 2.9 \\
\hline M25 & 9 & 2 Mar 2012 & $1401-1512$ & Clear & Daytime & 5.9 \\
\hline M26 & 9 & 2 Mar 2012 & $1706-1816$ & Clear & Daytime sunset & 8.5 \\
\hline M27 & 1 & 6 Mar 2012 & $1005-1115$ & Partly cloudy & Daytime & 4.5 \\
\hline M28 & 9 & 6 Mar 2012 & $1403-1514$ & Partly cloudy & Daytime & 7.7 \\
\hline M29 & 9 & 6 Mar 2012 & $1651-1801$ & Partly cloudy & Daytime sunset & 4.0 \\
\hline M30 & 9 & 7 Mar 2012 & 1801-1918 & Overcast & Nighttime & 5.7 \\
\hline M31 & 8 & 7 Mar 2012 & $2109-2225$ & Overcast with precipitation & Nighttime & 4.1 \\
\hline M32 & 8 & 7 Mar 2012 & $2346-0112^{*}$ & Overcast with precipitation & Nighttime & 2.7 \\
\hline
\end{tabular}

with 2-km searching radius, was also calculated based on the DEM. This parameter is used to reflect the influence of topography on temperature. Urban density, which is used to reflect the influence of urban heat islands on temperature, was calculated based on the land-use data with $25-\mathrm{m}$ spatial resolution. To calculate the urban density, the urban area was first identified and its point density with 1-km searching radius in ArcGIS desktop was used for the calculation. The sky-view factor, a dimensionless measurement that ranges from 0 to 1 to indicate the amount of visible sky at a certain location on the ground (Oke 1987), was used to reflect the influence of obstruction of the outgoing longwave radiation by objects surrounding the road, for example, the forest canopy. The shading effect, which ranges between 0 and 1 (fully shaded) as well, was used to reflect the blocking of incoming shortwave radiation to the road surface. A previous study (Hu et al. 2016) has shown that it is often important to consider the accumulated shading effect over several hours to account for the influence of direct shortwave radiation on the road surface. Therefore, the mean of accumulated shading percentage over three hours for each road segment was calculated in this study. The shading percentage for each road segment was calculated every $15 \mathrm{~min}$ and then interpolated based on

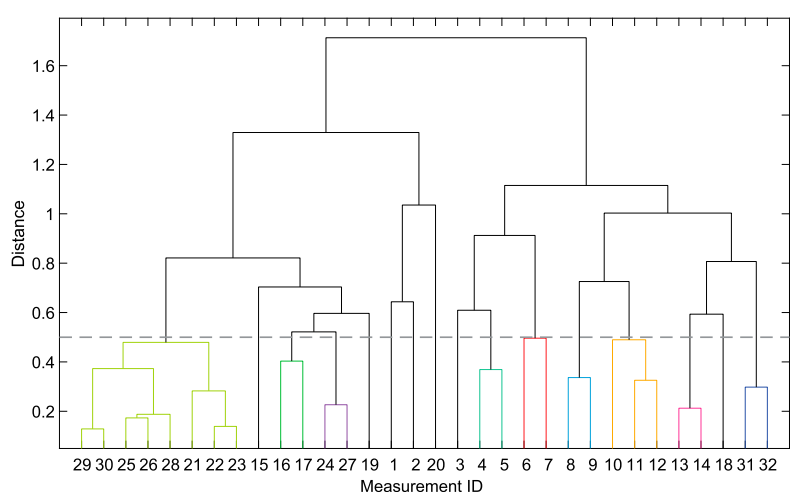

FIG. 2. Dendrogram showing the hierarchical clustering solution for the thermal-mapping measurements based on the correlation coefficient between every two measurements. The dashed line across the dendrogram shows the cutoff level. 

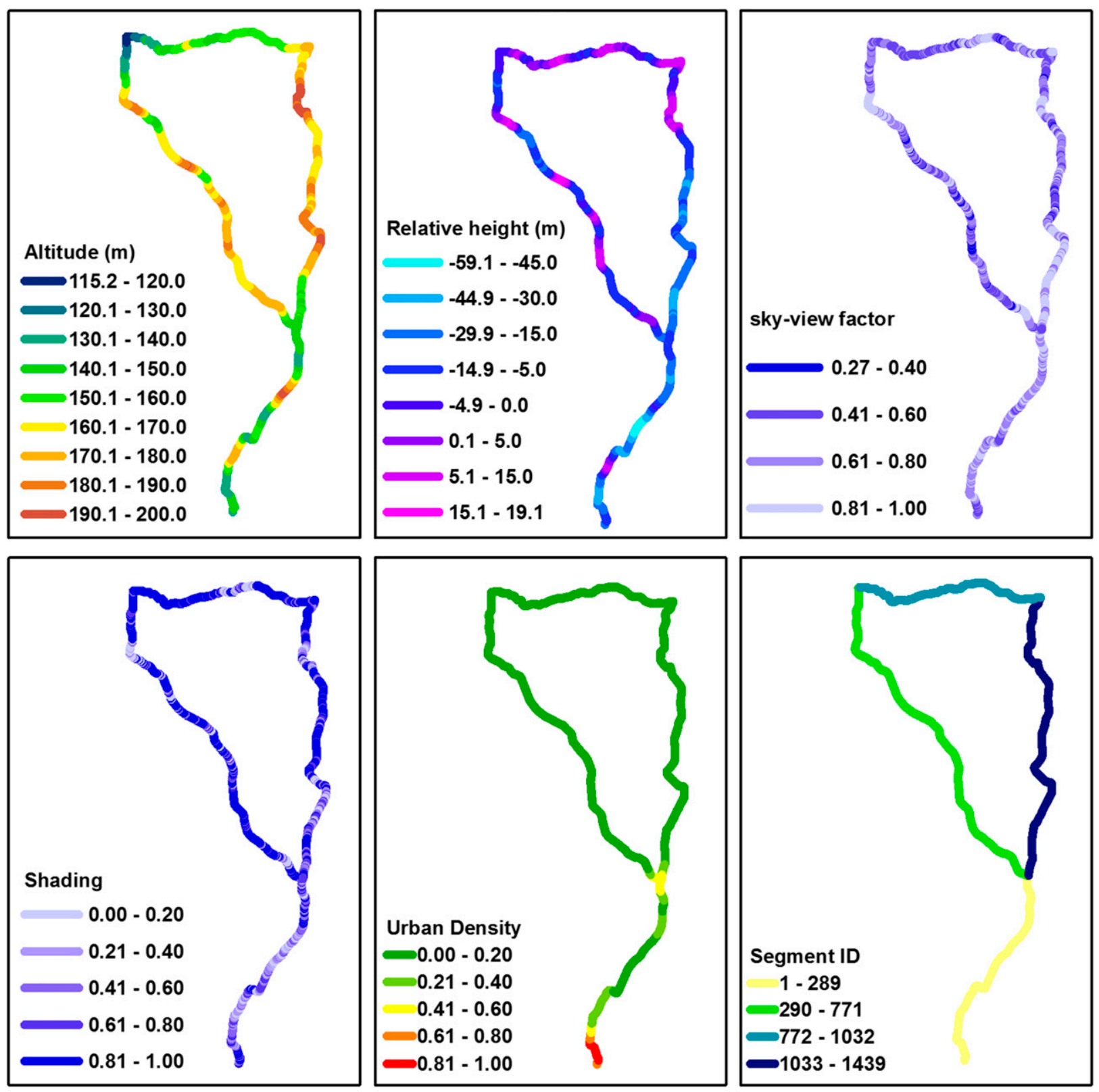

FIG. 3. Route-based segments for each geographical parameter.

time. For measurements during nighttime, the shading effect from three hours before sunset was used. Both $\psi_{s}$ and $\mathrm{S}_{\mathrm{r}}$ were computed using the DSM. For details of the calculation, see $\mathrm{Hu}$ et al. (2016).

The altitude, relative altitude, urban density, $\psi_{s}$, and $S_{r}$ vary greatly and have a clear pattern along the study route. Figure 3 shows the segment-based geographical parameters with 50-m spatial resolution. The altitude of the thermal route ranges between 115 and $200 \mathrm{~m}$, with relatively lower altitudes for the southern and northern parts of the route, and relatively higher altitudes for the route in the middle of the study area. In comparison to the surrounding area, the relative altitude of the thermal route is lower in the southern part of road 42 and over most of road 183 than other parts of the route. The map of $\psi_{s}$ shows relatively high values in the southern part compared to the northern part, where large areas of forest are located. The urban area is mainly located in the southern part, while the rural area is mainly located in the northern part. The shading effect is closely related to solar elevation, which depends on both time of year and time of day. Thus, only one example of $S_{r}$ for M26 is 
shown here. The number is dimensionless and ranges from 0 to 1 , representing the ratio of each road segment that was shaded. Corresponding to the pattern of $\psi_{s}$, the example shows a larger shading effect in the northern part.

\section{Results}

\section{a. Repeatability of thermal fingerprints and spatial patterns of $T_{a}$}

To build a model for spatial variation of RST between stations based on a group of thermal-mapping measurements, it is very important that the spatial pattern of each thermal fingerprint is repeatable under a given weather pattern. In addition, to model the spatial variation of RST using the same group of $T_{a}$ measurements, it is important that the spatial pattern of $T_{a}$ is also repeatable under the same given weather pattern. Figures $4 a-d$ show four groups containing thermal fingerprints that are related and considered as repeatable in this study. The corresponding spatial patterns of $T_{a}$ are shown in Figs. 4e-h. As shown, the variations of RST from different thermal-mapping runs are very similar. Comparing with Table 4, it seems that group 1 represents late winter morning runs with clear weather conditions, group 7 represents early winter evening runs with partly cloudy to overcast weather conditions, group 9 includes runs from late winter during different weather patterns and at different times, and group 16 mainly represents early winter from evening to late night runs during partly cloudy weather conditions. In general, the variation of RST in group 1 and group 9 is often very large, whereas the variation of RST in group 16 is relatively small. The variation of RST for measurements from the evening and nighttime is reduced in group 9. The variation of RST in group 7 is the least among the groups. However, for the same weather pattern, when the spatial variation of RST is repeatable, the spatial patterns of $T_{a}$ from different runs are not always similar (Figs. $4 \mathrm{e}-\mathrm{h}$ ), and, indeed, sometimes vary a great deal. The variation magnitude for $T_{a}$ is often much lower than for RST. Other groups that consist of thermal fingerprints from the same date are considered nonrepeatable and are not shown here.

\section{b. Influence of individual geographical parameters on RST and $T_{a}$}

For each thermal-mapping run, RST and $T_{a}$ were separately analyzed by calculating the partial correlation coefficient between the geographical parameters and each temperature variable. The results are shown in Figs. 5 and 6, respectively. The measurements are sorted by their group number.
For RST measurements in each identified repeatable group, it seems that the dominating parameters are the same (Fig. 5). For group 1, the influence of $S_{r}$ dominates. Road segments, which receive more direct shortwave radiation, have higher temperatures. For group 7, the influence of urban density dominates. Road segments, which are close to the urban area, tend to have higher temperatures. The second most influential parameter is $\psi_{s}$. Road segments with higher $\psi_{s}$ tend to lose more longwave radiation and have lower RST. Meanwhile, the accumulated shading shows a lagged influence on RST. Road segments that are more shaded tend to have lower RST. In this group, altitude also has some influence because of lapse rate. For group 9, the influence of $S_{r}$ and urban density dominates. RST tends to be higher in areas that are free from shading and close to urban areas. For group 16, the most influential parameter is $\psi_{s}$. RST is higher in areas that are surrounded by objects (e.g., trees or topography) and is lower with increasing altitude. Again, road segments that are close to the urban area have higher temperatures. For each repeatable group, the effects of relative altitude and altitude seem to compensate for each other, suggesting that the average altitude of the area is influential. (Relative altitude is defined as the difference between altitude and the average altitude of the area.)

For $T_{a}$, the dominating parameters were often altitude and urban density, and sometimes relative altitude (Fig. 6). The influence of $\psi_{s}$ and $S_{r}$ on $T_{a}$ was always very small. In comparison to the figures shown in Fig. 5, the dominating parameters were not always the same for measurements in the same group, especially for group 9. For $T_{a}$, the effects of relative altitude and altitude compensated for each other as well, which is similar to the relationship between RST and geographical parameters.

\section{c. Using $T_{a}$ and geographical parameters to model the spatial variation of $R S T$}

To test the applicability of the geographical parameters and the potential usability of $T_{a}$ from FCD, two stepwise linear regression models were built for each thermal-mapping run; one without $T_{a}$ and one including $T_{a}$. Figure 7 shows the performance of these two types of models. It is clearly shown that the inclusion of $T_{a}$ increases the explained variance of RST distribution in most cases. The average improvement for all the measurements is $10 \%$ and the highest improvement is up to $30 \%$. Relatively high improvement was often found for measurements recorded during overcast, overcast with precipitation or partly cloudy conditions.

The coefficients for each stepwise regression model, with $T_{a}$ included, are shown in Fig. 8. For each repeatable 

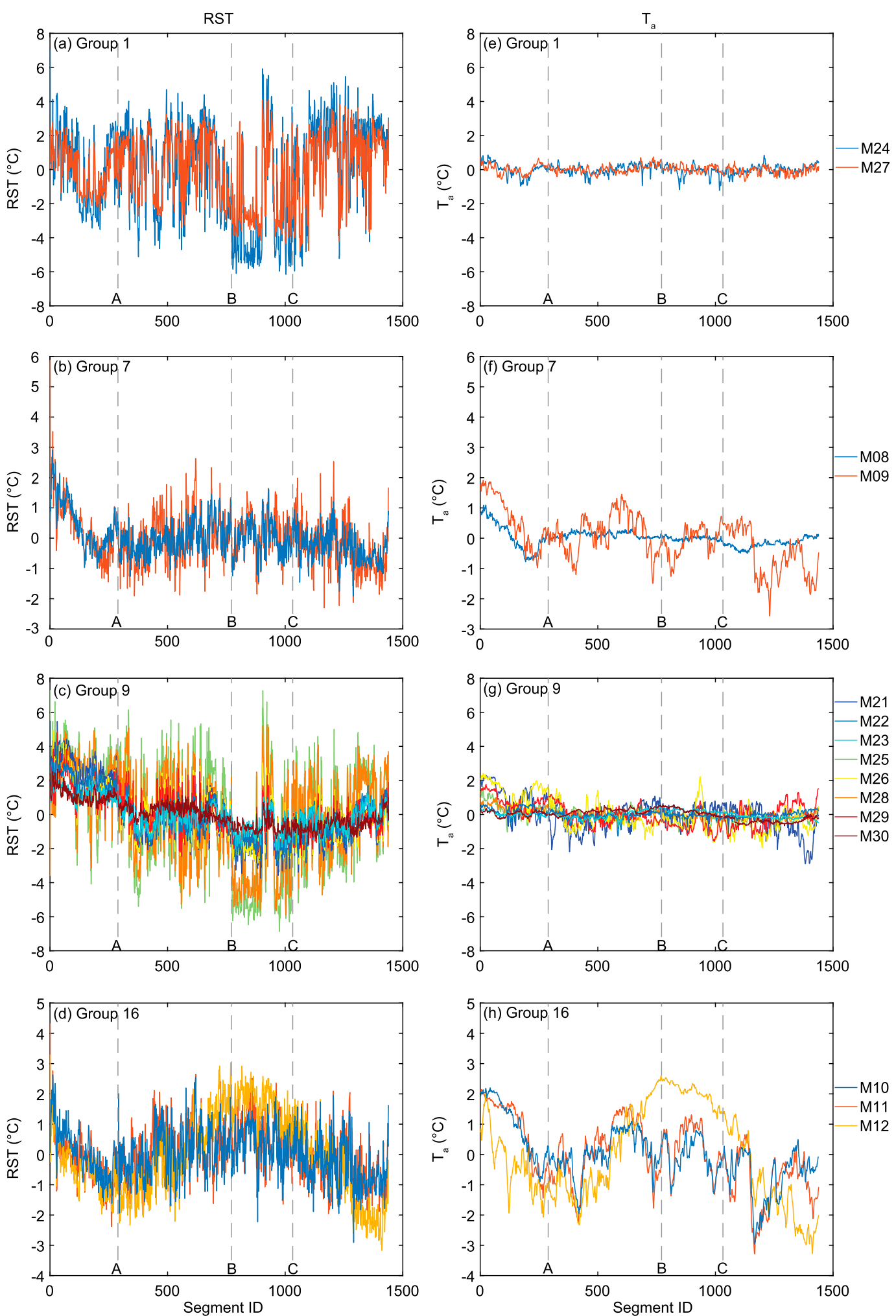

FIG. 4. Identified groups of thermal-mapping data and air temperature with repeatable thermal fingerprints. Labels $\mathrm{A}, \mathrm{B}$, and $\mathrm{C}$ show the control points during the thermal-mapping survey as shown in Fig. 1. 

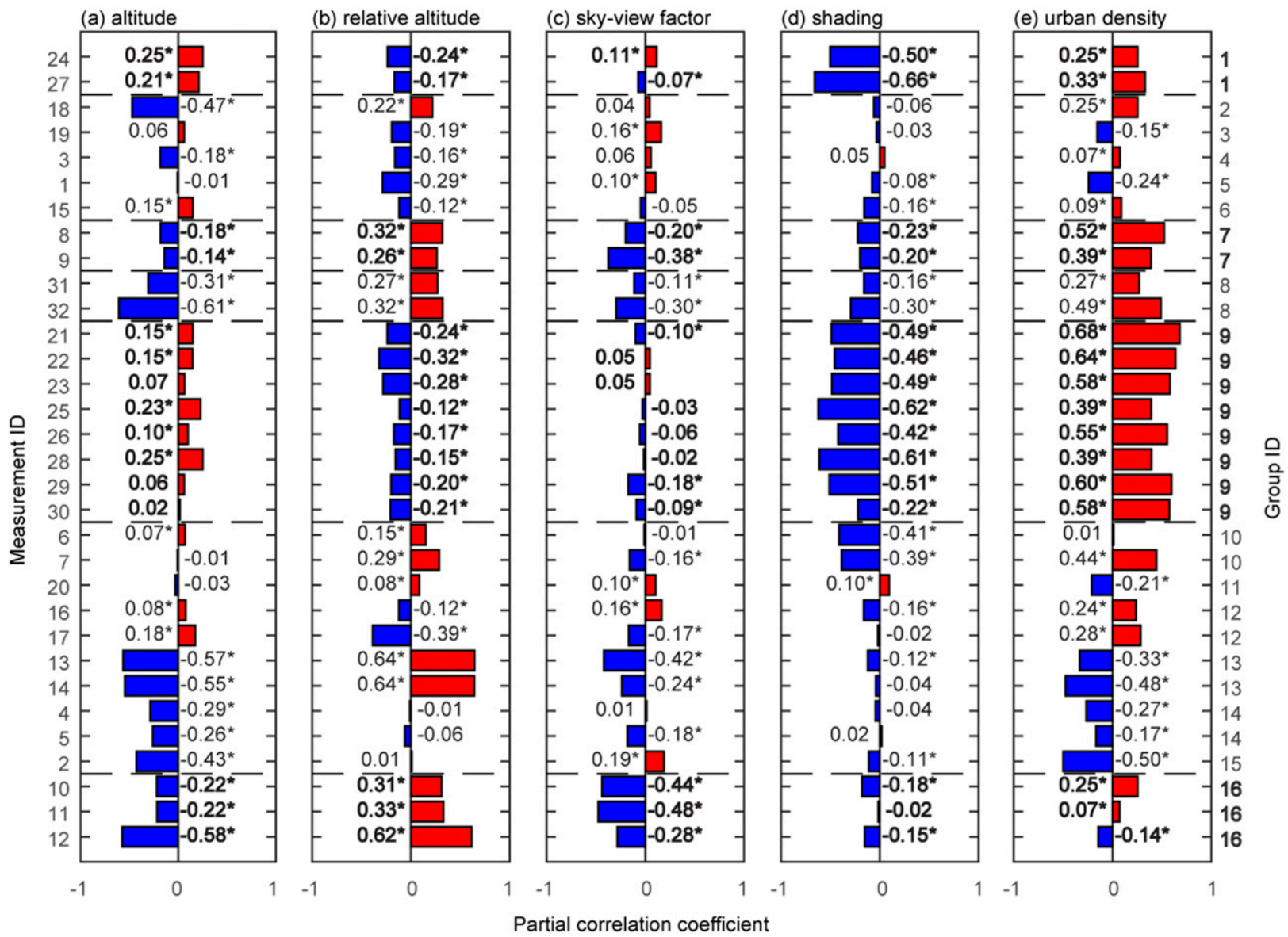

FIG. 5. Partial correlation coefficients between RST and the geographical parameters for each thermal mapping and their corresponding group number. Coefficients and group number for repeatable groups are shown in boldface type, and asterisks indicate models that are significant at the 0.01 level (2 tailed).

thermal-mapping group, the dominating parameters and their influence on RST are the same. $T_{a}$ is generally important for the modeling of RST under different weather conditions. The influence of different geographical parameters on RST, which was shown in Fig. 5, is also reflected in the stepwise regression models. Of all models for the repeatable thermal fingerprints groups, the highest explained variance of RST variation is up to $82 \%$ for group 16 , when RST is closely related to $T_{a}$ (Fig. 4).

In theory, for thermal mappings in the same group, the developed models should be similar so that the result could be used for road weather forecast models. However, as shown in section $3 b$, it is not always possible to use the relationship between $T_{a}$ and geographical parameters to reflect the influence of geographical parameters on the RST distribution, especially the influence of $\psi_{s}$ and $S_{r}$. Therefore, selecting the appropriate regression model based on weather, time of year or $T_{a}$ is a challenge, but the large improvements, by including
$T_{a}$ in the regression models, are promising for the usefulness of FCD.

\section{Discussion}

\section{a. Repeatability of temperature patterns}

This study shows that thermal fingerprints are repeatable over time with relatively high traffic volumes. The repeatable thermal fingerprints were often measured at similar times of the day or with similar weather patterns, for example, M25, M26, M28, and M29 in group 9 (Table 4). However, for the identified repeatable groups, there are some runs that were recorded at different times and weather patterns, mostly overcast conditions. Because of the heat storage in the road, it is necessary to examine the preceding weather patterns prior to each thermal-mapping survey. The total cloud information from meteorological analysis model Mesan was used to determine the cloud cover for each 

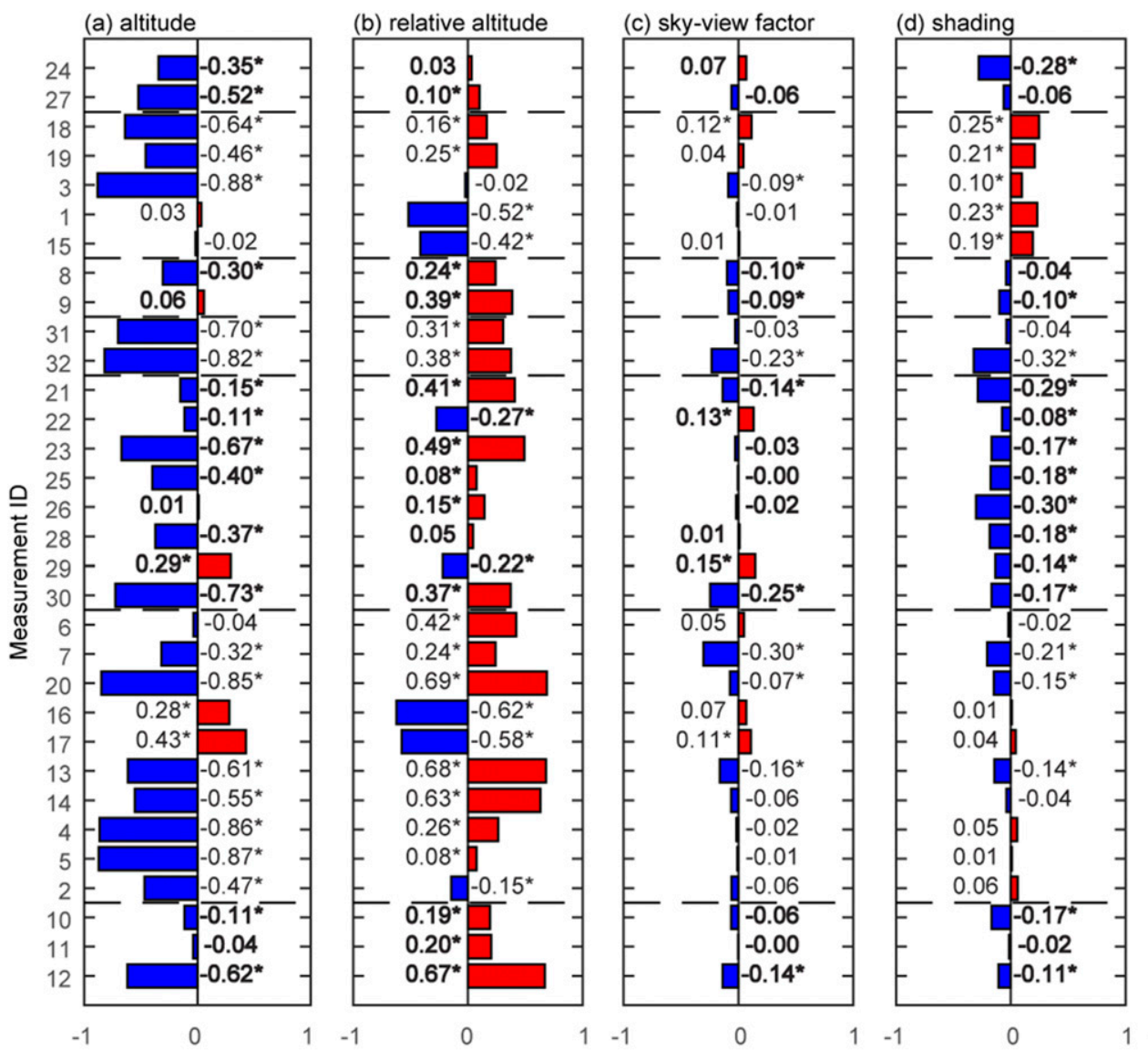

(e) urban density

Partial correlation coefficient

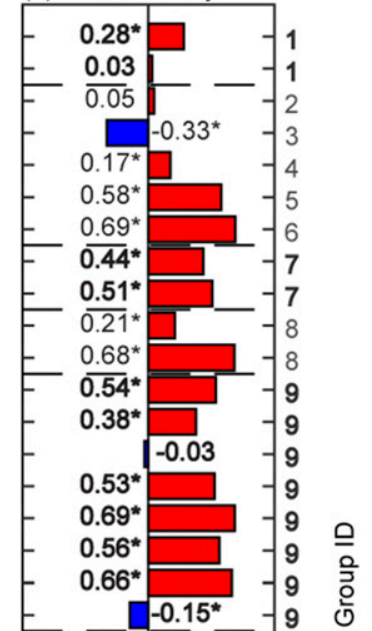

FIG. 6. Partial correlation coefficients between $T_{a}$ and the geographical parameters for each thermal mapping and their corresponding group number. Coefficients and group number for repeatable groups are shown in boldface type.

measurement in the study area. Figure 9 shows the cloud distribution every second hour back to sunrise for the dates on which repeatable thermal mapping was recorded. For M8 in group 7, the preceding weather changed from partly cloudy to overcast before noon and it seems the spatial pattern of RST formed during the daytime remained until later in the day. For M21, M22, and M23 in group 9, the weather was mostly clear in the afternoon that day. This created the spatial pattern of RST for clear conditions and remained until later in the night, when the weather changed to overcast. For M30 in group 9 , the preceding weather was partly cloudy until 1300 , which resulted in the difference in RST along the route. For M10 and M11, the preceding daytime weather was mostly partly cloudy conditions. In general, the preceding weather pattern exerts a strong influence on the spatial pattern of thermal mapping, especially for measurements recorded under overcast conditions. To some extent, the spatial pattern of RST, formed several hours prior to the measurements, often remains until the measurement is taken. A previous study (Hu et al. 2016) has shown that, for thermal-mapping measurements carried out under clear to partly cloudy weather conditions during daytime, it is often sufficient to consider

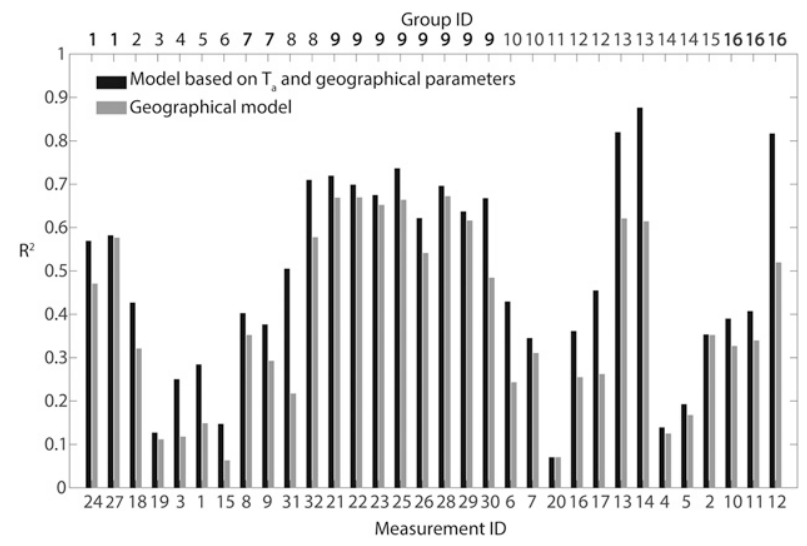

FIG. 7. The proportion of the variance in the RST distribution explained using models with $T_{a}$ included and without $T_{a}$ included. 

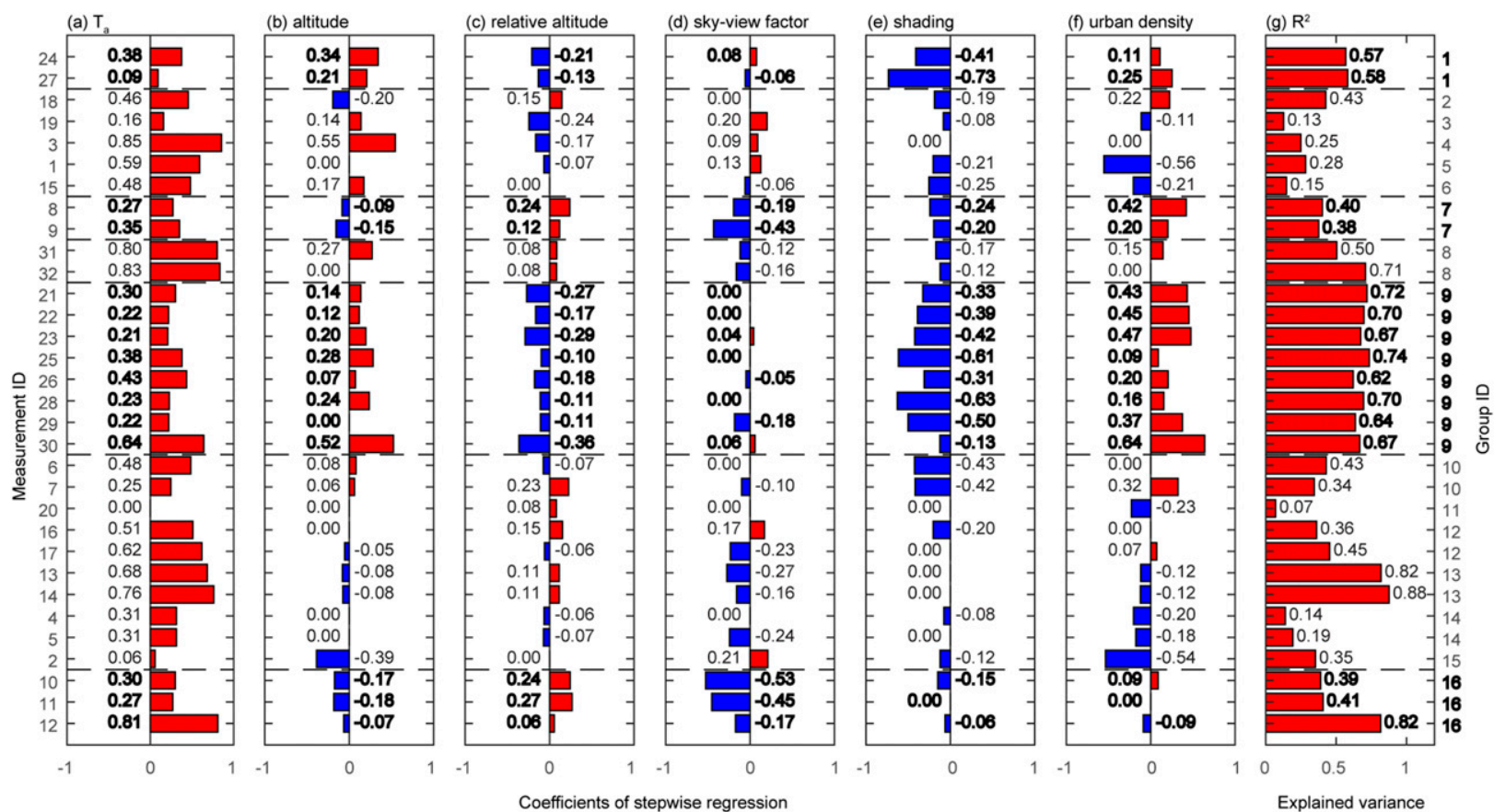

FIG. 8. Coefficients of stepwise regression model for RST based on $T_{a}$ and the geographical parameters for each thermal-mapping run and the corresponding weather group. All the models are significant at the 0.01 level ( 2 tailed). Coefficients and group number for repeatable groups are shown in boldface type.

the accumulated shading effect over the past three hours before the measurement was carried out. This is true for some cases in this study, for instance, M27, M28, and M29, which are highly correlated with the accumulated shading effects over the past three hours. However, this study shows that, for thermal-mapping measurements recorded under overcast weather conditions, especially close to or after sunset, the influence of the screening effect over a longer period, up to $12 \mathrm{~h}$, should be considered. This is in accordance with findings from Postgard (2001), which stated that it can take up to eight hours for the RST difference between sun-exposed sites and shaded sites, produced during clear day conditions, to react to overcast conditions. In addition, Bogren et al. (2000) indicated that the daytime RST difference caused by screening effects can remain up to four hours after sunset in early spring. Therefore, in order to classify future thermal-mapping measurements into the correct group, first the measurement time and corresponding real-time weather pattern should be checked. Then, the preceding weather pattern should be checked, especially for measurements during overcast conditions. In contrast to RST, the $T_{a}$ measurements are not always similar in each identified repeatable group for RST (Fig. 4). This is caused by the large differences in heat capacity between the air and the roadbed (Oke 1987). To increase the air and road surface temperatures by the same magnitude, the road surface requires much more heat than the air. Therefore, the air temperature reacts more quickly to real-time weather changes than the roadbed and the influence of the preceding weather conditions on $T_{a}$ is very limited. However, since the road emits and absorbs more radiation, the RST will change more than $T_{a}$ because of differences in shading and $\psi_{s}$. As mentioned above, some measurements were recorded under very different weather patterns from the others, which resulted in the different spatial patterns of $T_{a}$, even within groups.

\section{b. Similarity between RST and $T_{a}$}

Previous studies have shown that the variation in RST is closely related to the variation in $T_{a}$ (Gustavsson 1990; Bogren and Gustavsson 1991; Lindqvist 1992). However, as shown in Fig. 4, this is not always true for the thermal-mapping data used in this study. Figure 7 shows that $T_{a}$ is quite often influential when modeling RST, but as shown in Fig. 5 and 6, the $T_{a}$ and RST are not influenced by the same geographical parameters. The spatial variation of RST is often different from the pattern of $T_{a}$ recorded at the same time. This could be caused by the high ambient wind speed during the thermal-mapping survey. Bogren and Gustavsson (1991) indicated that variations in $T_{a}$ are completely smoothed out when the wind speed exceeds $3 \mathrm{~m} \mathrm{~s}^{-1}$ during the nighttime and this 


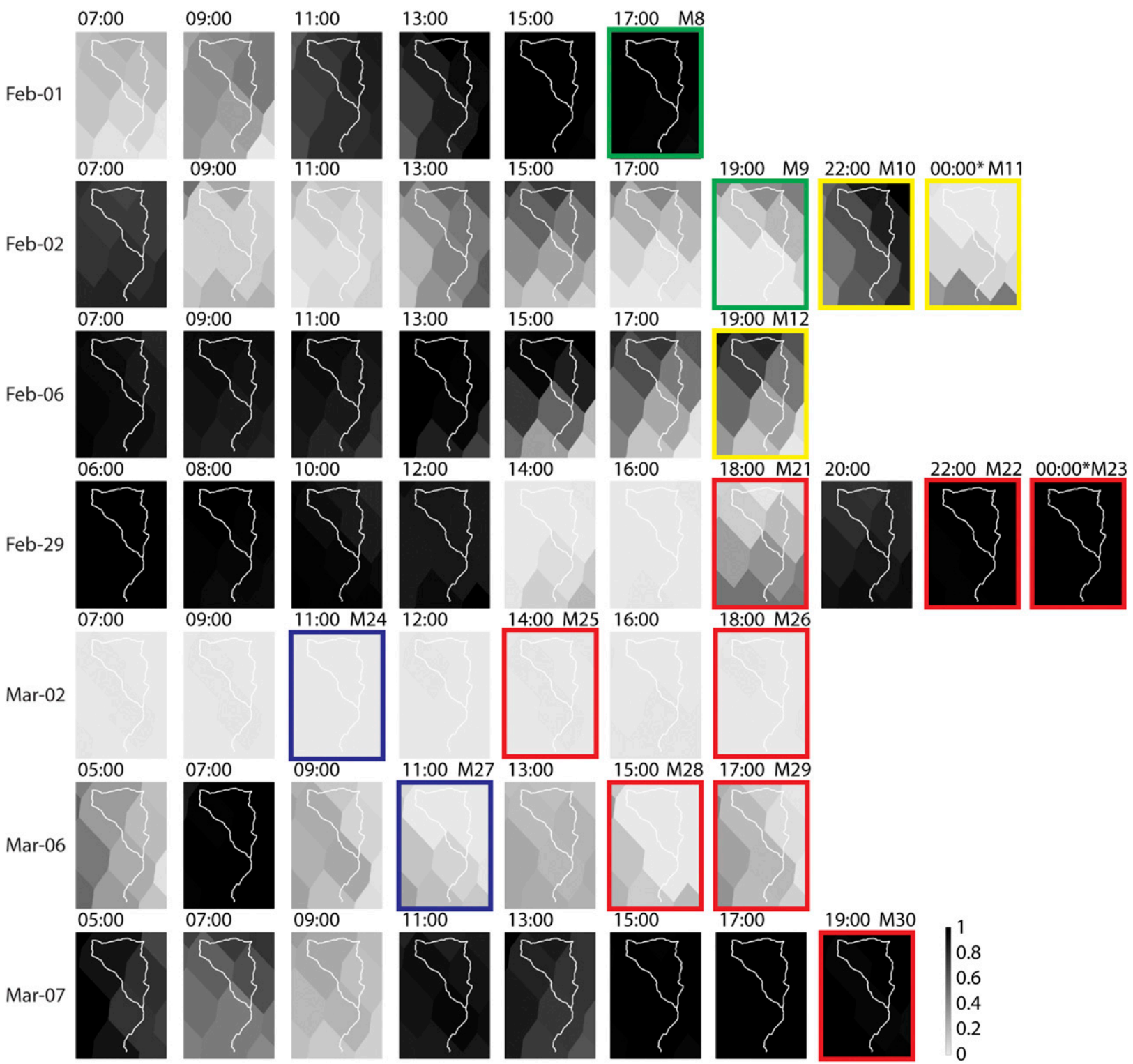

FIG. 9. Cloud conditions based on the Mesan data during and before each grouped thermal-mapping measurement. The asterisks indicate that the cloud condition is at the time shown on the top of the panel but for the following day from the date shown to the left of the row. Plots highlighted with rectangles show cloud conditions during the thermal-mapping time (blue: group 1; green: group 7; red: group 9; yellow: group 16).

smoothing effect is stronger with increasing cloud. The close relationships between RST and $T_{a}$ were all found during clear, calm conditions with wind speeds less than $1 \mathrm{~m} \mathrm{~s}^{-1}$ (Gustavsson 1990; Bogren and Gustavsson 1991; Lindqvist 1992), while in this study, nearly all the measurements were recorded with wind speeds exceeding $3 \mathrm{~m} \mathrm{~s}^{-1}$ (Table 4), with many of them recorded during partly cloudy to overcast conditions. Such conditions lead to low stability and more movement of air, which, in this case, resulted in small variations in the magnitude of $T_{a}$, while the variations in RST were still large because of the high heat capacity of the roadbed. These results confirm that research thus far into road climatology has mainly covered very rare weather and temperature patterns.

\section{c. Influence of geographical parameters}

The difference between spatial patterns of RST and $T_{a}$ is also shown in their relationships with geographical parameters. Under different weather patterns, there is a quite stable relationship between RST and different geographical parameters. For clear weather-related measurements, the influence of the shading effect dominates because of the influence of incoming shortwave 
radiation. For measurements recorded during peak traffic time, the high correlation with urban density reflects the influence caused by the increased traffic volume, thereby more heating from vehicles, for example, group 7. The influence of $\psi_{s}$ is mainly shown in measurements during nighttime, when the outgoing longwave radiation mainly influences the RST. During daytime, especially for measurements during clear or partly cloudy conditions, the influence of incoming shortwave radiation on RST is so strong that the influence of $\psi_{s}$ on the outgoing longwave radiation becomes negligible.

However, for $T_{a}$, the influence of geographical parameters is not as stable as for RST in each group, which is due to the low heat capacity of air. As discussed above, $T_{a}$ is sensitive to weather changes, so the spatial pattern of $T_{a}$ mainly depends on the real-time weather pattern. Because of the difference in the real-time weather pattern within most groups, the relationship between $T_{a}$ and geographical parameters is not stable for different runs in the same group. In comparison with the influence on RST, the influences of $S_{r}$ and $\psi_{s}$ on $T_{a}$ are very small. The influence on RST from $\psi_{s}$ and $S_{r}$ can be modeled reasonably well by using GIS information ( $\mathrm{Hu}$ et al. 2016); therefore, a road weather forecast model needs to take proper account of these parameters. A successful approach may be to construct special models to account for the influence of the parameters that are strongly related to RST, but not $T_{a}$, rather than to derive them from FCD. Still, the findings in Fig. 8 indicate that by combining geographical parameters and $T_{a}$, good results can be achieved.

\section{d. Indications}

The repeatability of thermal fingerprints and the stable models of RST based on $T_{a}$ and geographical parameters in the different repeatable groups, indicate that it is possible to model the RST distribution between stations for times with relatively high traffic volumes and for several different weather patterns.

It is clearly shown in Fig. 7 that the inclusion of $T_{a}$ can highly improve the explained variance of RST as compared with only using geographical parameters for most of the measurements. For RST measurements, which are highly influenced by the shading effect, for example, group 9, the improvements by including $T_{a}$ were generally small. This is due to the inability of using the relationship between shading effect and $T_{a}$ to reflect the influence of shading on RST (Figs. 5 and 6). For other weather conditions, for example, overcast, overcast with precipitation or partly cloudy, the improvements by including $T_{a}$ were higher, up to $30 \%$. This confirms the importance of mobile $T_{a}$ measurements in modeling
RST distribution between stations. It also indicates the importance and possible usability of $T_{a}$ from FCD to model the variation of RST between stations.

However, the repeatability of $T_{a}$ was not as encouraging as it was for RST. This makes it difficult to identify the correct group and thus regression model by only using mobile $T_{a}$ measurements and weather pattern information. This also indicates the difficulty in the application of $T_{a}$ from FCD. Further studies are needed to understand how to use $T_{a}$ to classify data into the correct repeatable groups.

\section{e. Challenges of replacing controlled $T_{a}$ measurements with FCD}

Private car drivers (Bucknall 2005; Lawrence 2006) have found that readings from in-car $T_{a}$ sensor highly agreed with $T_{a}$ measured by controlled sensors located in shade. This means a bright future application of $T_{a}$ from FCD in road weather forecasting. However, further investigations may still be needed before moving from controlled $T_{a}$ measurements to the full application of $T_{a}$ from FCD. As mentioned in section $2 \mathrm{~d}, T_{a}$ was recorded during the course of thermal mapping by installing a sensor on the roof of the vehicle at the height of $2 \mathrm{~m}$. On connected cars, the air temperature sensor is often placed inside of the side mirror housings, or inside the fenders or ahead of the vehicle's radiator. The measurement height of the $T_{a}$ sensors will vary depending on car model, which can result in difficulties in combining them in the same model for RST. The influence of direct shortwave radiation on $T_{a}$ from connected cars may be a problem. The lack of a radiation shield may be compensated by a large airflow across the sensor, especially when the cars move at high speed. The large quantity of measurements can also compensate for a lack in quality in sensor and measurement technique. This needs to be carefully studied before successfully moving from controlled measurements to floating measurements.

\section{f. Limitations}

In areas with more pronounced topography, one could expect to see other types of relationship between RST and $T_{a}$, where FCD could be useful in a different way than in this study. There were a number of thermalmapping runs with thermal fingerprints that were not considered repeatable from other measurement days. If more measurements were taken, it is possible that more groups of similar thermal fingerprints would emerge.

In the study area over the study time, there were very few occurrences of inversion, that is, clear calm nights, where cold air pooling occurred. Such cases would be identifiable by $T_{a} /$ RST having a positive correlation with 
both altitude and relative altitude, which were not present in the data. It may be possible to use $T_{a}$ from such situations to deduce RST, which is highly correlated with $T_{a}$ during clear calm nights, as seen in Gustavsson (1990) and Bogren and Gustavsson (1991). However, as shown in section 2, road users rarely encounter clear calm nights. Nevertheless, studies on clear calm nights are still important since the thermal amplitude that occurs during this type of weather is often large (Chapman and Thornes 2005). If water is present in some form on the road-rare as it may be during clear and calm weather-and minimum temperatures drop below $0^{\circ} \mathrm{C}$, the road still requires maintenance, since even a single car encountering such a situation can have serious consequences. On the other hand, as the results in this study clearly show, relying on thermal mapping taken on nights with clear and calm weather to represent the temperature variations that occur during other weather types (a common approach in road weather modeling currently) will give inaccurate results. As exemplified in Fig. 5, the thermal variations for $99 \%$ of the most often encountered weather types can be very different.

Note that the rare occurrence of clear, calm conditions in the study area could be caused by the mild winter climate in southwest Sweden. In a region with a continental climate, clear calm conditions may occur more than $2 \%$ of the time. Still, the distribution of traffic would probably be similar, so the likelihood of encountering clear and calm nights is, at most, a few percent.

\section{Conclusions}

Modern cars with road weather-related sensors connected to the cloud present an excellent opportunity to improve road weather forecast quality using FCD, which are often produced on roads with high traffic volumes and under different weather conditions. Most extant research has focused on clear and calm nights, which constitute a mere $0.3 \%$ of conditions road users will actually encounter while driving. Consequently, more than $99 \%$ of the FCD will be collected during largely unexamined weather and times of day. By utilizing 32 thermal-mapping and controlled $T_{a}$ surveys, mostly carried out on busy roads under different weather conditions in one winter season, the repeatability of thermal fingerprints, the stability of the influence of geographical parameters on temperature for thermal mapping with similar fingerprint patterns, and the potential to use $T_{a}$ from FCD and geographical parameters to build a geographical model for RST forecasting, were all examined. For the examined route, several repeatable thermal fingerprints were found during clear or clear-weather-related, partly cloudy, and overcast weather conditions. The measurement time and corresponding real-time weather pattern affect the patterns of thermal fingerprints. In addition, the preceding weather was important, especially for measurements recorded under overcast conditions.

For thermal mapping in the same repeatable group, the influence of geographical parameters on RST was also stable. The shading effect was most influential for late winter runs during clear or clear weather-related weather conditions. The urban density was most influential for evening runs with peak traffic or runs where conditions were clear weather-related. Relative altitude and altitude were most influential for measurements recorded during partly cloudy conditions later in the night.

However, in comparison to RST, the spatial pattern of $T_{a}$ was not as repeatable in each identified group and the magnitude of the variation was much smaller. For most of the runs, altitude and urban density were the two most influential parameters and could be used to reflect the influence of these parameters on RST, but the influence of hemisphere blocking and the shading effect could not be seen for $T_{a}$. Therefore, both $T_{a}$ and geographical parameters were used to build stepwise regression models for RST distribution between stations. The explained variance was up to $82 \%$, and the inclusion of $T_{a}$ in the regression models improved the model performance by up to $30 \%$ in comparison with the geographical models without $T_{a}$. This indicates that FCD can be useful for a road weather forecast model.

However, there are still many challenges when moving from controlled mobile $T_{a}$ measurements to $T_{a}$ measurements from floating cars. Further investigations are needed to understand how to best use FCD in road weather forecasting.

Acknowledgments. This research project was funded by the Swedish Transport Administration.

\section{REFERENCES}

Bogren, J., and T. Gustavsson, 1991: Nocturnal air and road surface-temperature variations in complex terrain. Int. J. Climatol., 11, 443-455, https://doi.org/10.1002/joc.3370110408.

,-- M. Karlsson, and U. Postgard, 2000: The impact of screening on road surface temperature. Meteor. Appl., 7, 97-104, https://doi.org/10.1017/S135048270000150X.

Bouris, D., T. Theodosiou, K. Rados, M. Makrogianni, K. Koutsoukos, and A. Goulas, 2010: Thermographic measurement and numerical weather forecast along a highway road surface. Meteor. Appl., 17, 474-484.

Brown, A., S. Jackson, P. Murkin, P. Sheridan, A. Skea, S. Smith, and S. Vosper, 2008: New techniques for route-based forecasting. Proc. 14th Standing Int. Road Weather Commission Conf., Prague, Czech Republic, 17, http://sirwec.org/ wp-content/uploads/Papers/2008-Prague/D-17.pdf. 
Bucknall, B. G., 2005: In praise of car thermometers. Weather, 60 (4), 98, https://doi.org/10.1256/wea.218.04.

Chapman, L., and J. E. Thornes, 2005: The influence of traffic on road surface temperatures: Implications for thermal mapping studies. Meteor. Appl., 12, 371-380, https://doi.org/10.1017/ S1350482705001957.

$\longrightarrow$, and - 2006: A geomatics-based road surface temperature prediction model. Sci. Total Environ., 360, 68-80, https:// doi.org/10.1016/j.scitotenv.2005.08.025.

,-- , and A. V. Bradley, 2001: Modelling of road surface temperature from a geographical parameter database. Part 1: Statistical. Meteor. Appl., 8, 409-419, https://doi.org/10.1017/ S1350482701004030.

Gustavsson, T., 1990: Variation in road surface temperature due to topography and wind. Theor. Appl. Climatol., 41, 227-236, https://doi.org/10.1007/BF00866454.

, 1999: Thermal mapping-A technique for road climatological studies. Meteor. Appl., 6, 385-394, https://doi.org/10.1017/ S1350482799001334.

— - and J. Bogren, 1991: Infrared thermography in applied road climatological studies. Int. J. Remote Sens., 12, 1811-1828, https://doi.org/10.1080/01431169108955211.

$\longrightarrow$, and - 1993: Evaluation of a local climatological modeltest carried out in the county of Halland, Sweden. Meteor. Mag., 122, 257-267.

—, M. Karlsson, J. Bogren, and S. Lindqvist, 1998: Development of temperature patterns during clear nights. J. Appl. Meteor., 37, 559-571, https://doi.org/10.1175/1520-0450(1998)037<0559: DOTPDC $>2.0 . \mathrm{CO} ; 2$.

Häggmark, L., K. I. Ivarsson, S. Gollvik, and P. O. Olofsson, 2000: Mesan, an operational mesoscale analysis system. Tellus, $\mathbf{5 2 A}$, 2-20, https://doi.org/10.3402/tellusa.v52i1.12250.

Hastie, T., R. Tibshirani, and J. Friedman, 2008: The Elements of Statistical Learning. Springer-Verlag, 763 pages.

Haurwitz, B., 1945: Insolation in relation to cloudiness and cloud density. J. Meteor., 2, 154-166, https://doi.org/10.1175/15200469(1945)002<0154:IIRTCA > 2.0.CO;2.

- 1946: Insolation in relation to cloud type. J. Meteor., 3, 123-124, https://doi.org/10.1175/1520-0469(1946)003<0123: IIRTCT $>2.0 . \mathrm{CO} ; 2$.

Hippi, M., P. Nurmi, and P. Saarikivi, 2008: Development Project ColdSpots: Towards more detailed road condition forecasts. Proc. 14th Standing Int. Road Weather Commission Conf., Prague, Czech Republic, 26, http://sirwec.org/wp-content/ uploads/Papers/2008-Prague/D-26.pdf.

Hu, Y., E. Almkvist, F. Lindberg, J. Bogren, and T. Gustavsson, 2016: The use of screening effects in modelling route-based daytime road surface temperature. Theor. Appl. Climatol., 125, 303-319, https://doi.org/10.1007/s00704-015-1508-9.

Karlsson, I. M., 2000: Nocturnal air temperature variations between forest and open areas. J. Appl. Meteor., 39, 851-862, https://doi.org/10.1175/1520-0450(2000)039<0851: NATVBF $>2.0 . \mathrm{CO} ; 2$.

Karsisto, V., and P. Nurmi, 2016: Using car observations in road weather forecasting. Proc. 18th Standing Int. Road Weather Commission Conf., Fort Collins, CO, 17, http://sirwec.org/ wp-content/uploads/Papers/2016-FtCollins/D-017.pdf.

Lawrence, C. B., 2006: Measuring temperature with car thermometers. Weather, 61 (2), 59, https://doi.org/10.1256/ wea.103.05.

Lindqvist, S., 1992: Local climatological modelling for road stretches and urban areas. Geogr. Ann., 74A, 265-274, https:// doi.org/10.1080/04353676.1992.11880369.
Mahoney, W. P., and J. M. O'Sullivan, 2013: Realizing the potential of vehicle-based observations. Bull. Amer. Meteor. Soc., 94, 1007-1018, https://doi.org/10.1175/BAMS-D-12-00044.1.

Mahrt, L., 2011: The near-calm stable boundary layer. Bound.Layer Meteor., 140, 343-360, https://doi.org/10.1007/s10546011-9616-2.

Marchetti, M., M. Moutton, S. Ludwig, L. Ibos, V. Feuillet, and J. Dumoulin, 2011: Road networks winter risk estimation using on-board uncooled infrared camera for surface temperature measurements over two lanes. Int. J. Geophys., 2011, 514970, http://dx.doi.org/10.1155/2011/514970.

— , L. Chapman, A. Khalifa, and M. Bues, 2014: New role of thermal mapping in winter maintenance with principal components analysis. Adv. Meteor., 2014, 254795, http://dx.doi.org/ 10.1155/2014/254795.

_ A. Khalifa, and M. Bues, 2015: Methodology to forecast road surface temperature with principal components analysis and partial least-square regression: Application to an urban configuration. Adv. Meteor., 2015, 562621, http://dx.doi.org/ 10.1155/2015/562621.

Morris, D., G. Madzudzo, and A. Garcia-Perez, 2018: Cybersecurity and the auto industry: The growing challenges presented by connected cars. Int. J. Automot. Technol. Manag., 18, 105-118, https://doi.org/10.1504/IJATM.2018.092187.

Oke, T. R., 1987: Boundary Layer Climates. Psychology Press, $435 \mathrm{pp}$.

Pasquill, F., and F. B. Smith, 1983: Atmospheric Diffusion. 3rd ed. Ellis Horwood, 336 pp.

Petty, K. R., and W. P. Mahoney, 2007: Weather applications and products enabled through vehicle infrastructure integration. Federal Highways Administration Tech. Rep. FHWA-HOP07-084, 124 pp.

Postgard, U., 2001: Adjustment time for road surface temperature during weather changes. Meteor. Appl., 8, 397-407, https:// doi.org/10.1017/S1350482701004029.

Postgård, U., and S. Lindqvist, 2001: Air and road surface temperature variations during weather change. Meteor. Appl., 8 , 71-83, https://doi.org/10.1017/S1350482701001062.

Saarikivi, P., M. Hippi, P. Nurmi, and J. Sipilä, 2008: Observing the variability of road and weather conditions with hybrid mobile and fixed sensors. Proc. 14th Standing Int. Road Weather Commission Conf., Prague, Czech Republic, 10, http:// sirwec.org/wp-content/uploads/Papers/2008-Prague/D-10.pdf.

Shao, J., 2000: Fuzzy categorization of weather conditions for thermal mapping. J. Appl. Meteor., 39, 1784-1790, https:// doi.org/10.1175/1520-0450-39.10.1784

_ _ and P. Lister, 1995: Data filtering for thermal mapping of road surface temperatures. Meteor. Appl., 2, 131-135, https:// doi.org/10.1002/met.5060020206.

_ - _ G. Hart, and H. Pearson, 1996: Thermal mapping: Reliability and repeatability. Meteor. Appl., 3, 325-330, https://doi.org/10.1002/met.5060030405.

_ J. C. Swanson, R. Patterson, P. J. Lister, and A. N. McDonald, 1997: Variation of winter road surface temperature due to topography and application of thermal mapping. Meteor. Appl., 4, 131-137, https://doi.org/10.1017/S135048279700042X.

Thornes, J. E., 1991: Thermal mapping and road-weather information systems for highway engineers. Highway Meteorology, A. H. Perry and L. J. Symons, Eds., Taylor and Francis, 39-67.

Todeschini, I., and Coauthors, 2016: Thermal mapping as a valuable tool for road weather forecast and winter road maintenance: An example from the Italian Alps. Proc. SPIE, 9688, 96880H, https://doi.org/10.1117/12.2240484. 